\title{
Superior outcomes for repair in infants and neonates with tetralogy of Fallot with absent pulmonary valve syndrome
}

\author{
Jonathan M. Chen, MD, ${ }^{a}$ Julie S. Glickstein, MD, ${ }^{b}$ Renee Margossian, MD, ${ }^{\mathrm{c}}$ Michelle L. Mercando, BA, ${ }^{d}$
} William E. Hellenbrand, MD, Ralph S. Mosca, MD, ${ }^{d}$ and Jan M. Quaegebeur, MD ${ }^{d}$

From the Department of Cardiothoracic Surgery, Weill Medical School at Cornell University, New York, NYa; the Divisions of Cardiothoracic Surgery, ${ }^{\mathrm{b}}$ and Pediatric Cardiology, ${ }^{\mathrm{c}}$ Columbia University College of Physicians and Surgeons, New York, NY; and the Division of Pediatric Cardiology, Harvard Medical School, Cambridge, Mass. ${ }^{\mathrm{d}}$

Presented at the Seventy-fifth Annual Meeting of the American Academy of Pediatrics, Washington, DC, October 8, 2005.

Received for publication April 5, 2006; revisions received May 12, 2006; accepted for publication May 22, 2006.

Address for reprints: Jonathan M. Chen, MD, Department of Cardiothoracic Surgery, Weill Medical School at Cornell University, 525 E. 68th Street, Box 110-Suite F695B, New York, NY 10021 (E-mail: jmc23@ columbia.edu).

J Thorac Cardiovasc Surg 2006;132:1099-104 0022-5223/ $\$ 32.00$

Copyright $\odot 2006$ by The American Association for Thoracic Surgery

doi:10.1016/j.jtcvs.2006.05.049
Objective: Primary repair of tetralogy of Fallot with absent pulmonary valve syndrome has been associated with significant mortality, particularly for neonates in respiratory distress. Controversy persists regarding the method of establishing right ventricle-pulmonary artery continuity.

Methods: Anatomic and demographic parameters were evaluated for patients undergoing repair of tetralogy of Fallot with absent pulmonary valve syndrome from 1990 to 2005, as were perioperative and late postoperative parameters (airway complications, reoperation or catheter-based intervention, and mortality).

Results: Twenty-three patients underwent repair. Median age was 15 days (range 2-1154 days). Patients were followed up for $5.3 \pm 3.9$ years. Seventeen $(85 \%)$ required preoperative ventilatory assistance. One patient died within 24 hours; 1 patient died 8 months postoperatively. Four patients received valved homografts, and the remainder had valveless connections. All patients underwent reduction pulmonary arterioplasty and mobilization, unifocalization (in 3), and ventricular septal defect closure. Valveless connection recipients had a transannular hood. No patient underwent a Lecompte maneuver. Four patients underwent reoperation for conversion to valveless connection $(\mathrm{n}=1)$, reduction arterioplasty $(\mathrm{n}=1)$, and repair of pulmonary stenosis $(\mathrm{n}=2)$. Three patients required catheter-based intervention, with balloon angioplasty $(\mathrm{n}=3)$ and stent placement $(\mathrm{n}=1) ; 2$ now demonstrate equal quantitative lung perfusion. No patient has had significant debility from airway compromise. All patients demonstrate free pulmonary insufficiency and good biventricular function.

Conclusions: We report excellent overall survival (89\%) and low postoperative morbidity for neonates and infants undergoing primary repair of tetralogy of Fallot with absent pulmonary valve syndrome. Our recent experience supports the use of a valveless right ventricle-pulmonary artery connection, which, combined with catheter-based intervention, reduces the likelihood of reoperation necessitated by homograft placement.

$\mathrm{T}$ etralogy of Fallot (TOF) with absent pulmonary valve syndrome (APV) is an unusual variant of TOF, the primary repair of which has traditionally been associated with significant morbidity and mortality, especially for neonates with respiratory distress. Mortalities as high as 33\% have been reported for neonates and infants with TOF-APV, and although recent surgical series have suggested improving perioperative survivals, the rates of reintervention for these patients remain high. In particular, for those receiving homografts, reoperation is obligatory. ${ }^{1-4}$

Although most concur regarding the need for early intervention with TOF-APV to reduce the extent and severity of tracheal stenosis and bronchomalacia, considerable debate persists regarding the best method of right ventricle (RV)-pulmonary 


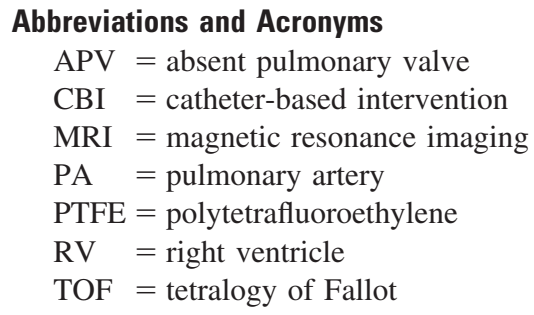

artery (PA) connection, as well as the most efficacious surgical management of the dilated PAs. Techniques reported have included the complete excision of the dilated PAs and reconstruction with homograft tissue, performance of a Lecompte maneuver, subtotal resection with flap augmentation and arteriopexy, and anterior or posterior resection and reduction pulmonary angioplasty. ${ }^{1-6}$

We reviewed our 15-year experience with repair of TOFAPV. Particular attention was paid to the method of RV-PA connection and its impact on medium-term results.

\section{Methods \\ Patients}

Records were reviewed of all patients with TOF-APV repaired between April 1, 1990, and April 1, 2005, at the Morgan Stanley Children's Hospital of New York-Presbyterian Hospital. Preoperative anatomic and demographic parameters were evaluated, including fetal diagnosis, initial presentation, presence of chromosomal abnormalities, age and weight at surgery, the need for preoperative ventilatory support, and additional congenital heart defects.

Early and late postoperative morbidities were also evaluated, including airway complications, total mechanical ventilatory time, intensive care unit and overall hospital stays, the need for reoperation or catheter-based intervention (CBI), long-term respiratory morbidity, and overall mortality. Most recent echocardiograms were reviewed to assess ventricular function, residual defects, degree of pulmonary insufficiency, RV parameters, and right-sided outflow tract obstruction. Telephone interviews with parents and referring cardiologists were performed to assess overall growth and development, the degree of residual respiratory compromise, and exercise tolerance.

This study was approved by the Columbia University institutional review board.

\section{Surgical Technique}

All patients underwent complete repair of the lesion, involving closure of the ventricular septal defect (by transventricular $[n=14]$ or transatrial $[n=5]$ approach), resection of the infundibular stenosis, downsizing of the PAs, and establishment of RV-PA continuity. Pulmonary reduction arterioplasty involved a generous anterior arterioplasty with primary reapproximation. All patients underwent extensive mobilization of both PAs from hilum to hilum, with maximum liberation of the branch PAs off the bronchus. No patient had the dilated PAs completely excised. All branch PAs underwent reduction angioplasty to an appropriate size, as esti- mated by body surface area. The Lecompte maneuver was not performed. For patients in whom the PA arose anomalously from the aorta, the branch PAs were additionally unifocalized before establishment of RV-PA continuity. For patients in whom reconstruction with a simple transannular patch would result in PA distortion, the main PA was completely excised from the ventricle, and the PA bifurcation was brought directly to the shoulder of the ventricle at the superior aspect of the right ventriculotomy.

RV-PA continuity was established with either (1) a valved homograft, or (2) a valveless transannular patch, with a hood of material (either autologous pericardium or polytetrafluoroethylene [PTFE]) used as a roof over the connection. No patients with the transannular patch had reconstruction with monocusp valves.

\section{Interventional Techniques}

For patients with evidence of stenosis of the branch PAs on postoperative evaluation, further inquiry regarding the distribution of flow was determined with ventilation-perfusion nucleotide scanning or magnetic resonance imaging (MRI). Cardiac catheterization was used diagnostically and therapeutically, and intervention was pursued for those with focal lesions, for those with significantly elevated RV pressures, and for those in whom maldistribution of perfusion exceeded $70 \% / 30 \%$.

\section{Results}

\section{Demographics}

Twenty-three patients underwent operation for TOF-APV during the study period at MS-CHONY (Table 1). There were 10 male and 13 female patients. Two patients had undergone operative repair elsewhere and required RV-PA conduit exchanges, and 1 patient returned to a foreign country and was unavailable for follow-up evaluation; these 3 patients were not included in the analysis. One patient had undergone repair elsewhere as a neonate but required revision as an infant at MS-CHONY. The other 19 patients underwent their primary operations at MS-CHONY. The mean follow-up was $5.3 \pm 3.9$ years (range $1.1-13.5$ years).

The median age of the patients was 15 days (range 2-1154 days). The average weight of the patients was $4.0 \pm$ $2.1 \mathrm{~kg}$ (range $2-11.8 \mathrm{~kg}$ ). The most common presentation was respiratory distress at birth, in 17 patients $(85.0 \%) ; 2$ patients were completely symptom free, and an additional 2 were initially symptom free but required reevaluation at 14 to 21 days of age for airway compromise and respiratory symptoms. Seventeen patients $(85.0 \%)$ required preoperative ventilatory assistance, ranging from continuous positive airway pressure (CPAP, $\mathrm{n}=10$ ) to intubation with mechanical ventilation $(n=7)$.

The diagnosis of TOF-APV had been made prenatally in 7 cases $(35.0 \%)$. Apart from atrial septal defects, no patient demonstrated other significant cardiac anomalies requiring reconstruction at the time of repair; however, 2 patients had discontinuous branch PAs requiring unifocalization. No patients demonstrated coronary artery anomalies. Two 
TABLE 1. Patient characteristics

\begin{tabular}{|c|c|c|c|c|}
\hline$\overline{\text { Case }}$ & Age (d) & Preoperative ventilation & Operation & Outcome \\
\hline 1 & 2 & CPAP & Homograft reconstruction & Well at follow-up \\
\hline 2 & 2 & Intubated & $\begin{array}{l}\text { Transannular patch of autologous } \\
\text { pericardium }\end{array}$ & Died perioperatively \\
\hline 3 & 4 & Intubated & $\begin{array}{l}\text { Transannular patch of autologous } \\
\text { pericardium }\end{array}$ & Well at follow-up \\
\hline 4 & 4 & Intubated & Direct connection with PTFE hood & $\begin{array}{l}\text { Balloon angioplasty, reoperation, } \\
\text { PA stent }\end{array}$ \\
\hline 5 & 6 & CPAP & $\begin{array}{l}\text { Unifocalization, transannular patch of } \\
\text { homograft pericardium }\end{array}$ & Reoperation, PA stent \\
\hline 6 & 7 & CPAP & Unifocalization, homograft reconstruction & Well at follow-up \\
\hline 7 & 8 & CPAP & Transannular patch of PTFE & Well at follow-up \\
\hline 8 & 12 & CPAP & Transannular patch of PTFE & Balloon angioplasty, PA stent \\
\hline 9 & 13 & CPAP & $\begin{array}{l}\text { Transannular patch of autologous } \\
\text { pulmonary tissue }\end{array}$ & Well at follow-up \\
\hline 10 & 13 & Intubated & $\begin{array}{l}\text { Transannular patch of autologous } \\
\text { pericardium }\end{array}$ & Well at follow-up \\
\hline 11 & 17 & Asymptomatic & $\begin{array}{l}\text { Unifocalization, direct connection with } \\
\text { PTFE hood }\end{array}$ & Well at follow-up \\
\hline 12 & 20 & CPAP & Transannular patch of PTFE & Died 8 months postoperatively \\
\hline 13 & 22 & CPAP & Direct connection with PTFE hood & Well at follow-up \\
\hline 14 & 24 & Symptomatic at $21 \mathrm{~d}$ & $\begin{array}{l}\text { Transannular patch of autologous } \\
\text { pericardium }\end{array}$ & $\begin{array}{l}\text { Reoperation, reduction } \\
\text { pulmonary arterioplasty }\end{array}$ \\
\hline 15 & 29 & Intubated & Homograft reconstruction & Well at follow-up \\
\hline 16 & 33 & Intubated & Homograft reconstruction & Conversion to direct connection \\
\hline 17 & 40 & Asymptomatic & $\begin{array}{l}\text { Transannular patch of autologous } \\
\text { pericardium }\end{array}$ & Well at follow-up \\
\hline 18 & 231 & Asymptomatic & $\begin{array}{l}\text { Transannular patch of autologous } \\
\text { pericardium }\end{array}$ & Well at follow-up \\
\hline 19 & 238 & $\begin{array}{l}\text { Late respiratory } \\
\text { symptoms }\end{array}$ & Transannular patch of PTFE & Well at follow-up \\
\hline 20 & 1154 & $\begin{array}{l}\text { Tracheostomy, ventilator } \\
\text { dependent }\end{array}$ & Transannular patch of PTFE & Well at follow-up \\
\hline
\end{tabular}

$C P A P$, continuous positive airway pressure; PTFE, polytetrafluoroethylene; $P A$, pulmonary artery.

patients $(10.0 \%)$ had chromosomal study results consistent with DiGeorge syndrome.

\section{Operations and Perioperative Parameters}

The earliest 4 patients underwent repair with a homograft for the RV-PA connection; the remainder of the patients received valveless connections. In 1 patient who was seen electively for planned reoperative homograft exchange, the PA bifurcation was instead brought to the shoulder of the $\mathrm{RV}$, and the homograft was converted to a valveless RV-PA connection with the "direct connection" technique we have described previously. ${ }^{7}$ In 2 patients, the direct connection technique was used at the time of primary repair; both with PTFE used as the hood of the connection. Among the 13 other patients receiving transannular patches, 4 had PTFE used, 1 had PA tissue excised from the dilated branch PAs used, 1 had homograft PA used, and 7 had autologous pericardium tanned in glutaraldehyde used. Three patients required unifocalization of the branch PAs before repair.
Postoperative mechanical ventilatory assistance duration was $4.1 \pm 2.3$ days, followed by CPAP for $2.9 \pm 1.6$ days in 10 cases. Postoperative intensive care unit stay was $13.9 \pm 18.7$ days; overall hospital stay was $16.5 \pm 20.9$ days.

Two patients died after operation. The first (patient 2), who died at 48 hours, was an infant initially brought to the operating room at 36 hours after birth, having sustained an acute cardiopulmonary arrest. During the first 24 hours after birth, he had significant ventilation difficulties, requiring an oscillation ventilator, with a $\mathrm{PCO}_{2}$ as high as $180 \mathrm{~mm} \mathrm{Hg}$. In the operating room, he again sustained a cardiopulmonary arrest, and despite weaning appropriately from cardiopulmonary bypass after the repair, he could not be supported in the perioperative period.

The second patient (patient 12) was transferred back to her referring hospital on postoperative day 64 with CPAP. At the referring hospital, she underwent tube gastrostomy, complicated by a pericatheter abscess requiring intravenous 
antibiotics. Approximately 8 months postoperatively, she had a respiratory arrest. Despite endotracheal intubation, she could not be sufficiently oxygenated and died.

\section{Echocardiography}

The most recent echocardiographic analysis $(2.7 \pm 4.2$ years after repair) demonstrated free pulmonary insufficiency in all patients, including those with homograft RV-PA connections. No patients demonstrated a residual ventricular septal defect, and only 1 demonstrates a $40-\mathrm{mm}$ $\mathrm{Hg}$ gradient in the RV outflow tract. One patient demonstrates a severely dilated RV with reduced ventricular function; the others all display a moderate degree of ventricular dilatation with normal RV function and diastolic flattening of the interventricular septum.

\section{Reoperations}

Four patients required reoperation. Patient 4 had a direct connection type repair at the time of initial operation. Although he made an uneventful recovery, he subsequently demonstrated a discrete narrowing of his distal main PA, necessitating balloon dilatation 3 months later. He returned to the operating room 4 months later for patch augmentation of the stenotic distal PA thought to be related to the acute angle of origin of the right branch PA. Despite this, the patient had a recurrence of distal main PA stenosis, necessitating stent placement at 22 months of age; he has subsequently demonstrated balanced pulmonary blood flow on follow-up MRI examination.

Patient 5 initially required unifocalization of her PAs because of the origin of her left branch PA from the ascending aorta. She had a transannular patch of cryopreserved pericardium. She returned to the operating room 3 weeks later for repair of severe left branch PA stenosis. At operation, her left PA origin at the site of unifocalization arose at a significant angle and in addition was severely fibrotic, thought to be due to the presence of ductal tissue. The fibrosis was resected, and the left branch PA was brought to the distal aspect of the previous transannular patch and additionally augmented with cryopreserved pericardium. Despite an uneventful recovery, this child later required a left PA stent at 10 months of age; she has since demonstrated balanced pulmonary blood flow.

Patient 14 had initial repair with a reduction pulmonary arterioplasty and a transannular patch of autologous pericardium. She had an uneventful recovery from this procedure but was seen 2 years later with persistent respiratory complaints and a ventilation-perfusion scan demonstrating $77 \%$ of flow to the right lung. She subsequently underwent reoperation. At the time of operation, the etiology of the recurrent dilatation was unclear; however, the dilation was more pronounced on the left than the right main PA. In addition, the arborization of the left PA was highly abnormal, and the tertiary branches were diminutive. The patient subsequently underwent a repeat reduction arterioplasty of both right and left main branch PAs. She has since had a follow-up MRI demonstrating no evidence of focal PA stenosis, but ventilation-perfusion scanning continues to demonstrate unbalanced perfusion.

Patient 16 initially had undergone repair with an 11-mm homograft and was brought to the operating room electively 3 years later for homograft exchange. At the time of the operation, it was clear that the PA bifurcation would reach easily to the ventricle, and a direct connection conversion with an autologous pericardial hood was therefore completed.

The final patient (patient 20) had been operated on previously at another institution and had remained ventilator dependent with a tracheostomy and severe bronchomalacia. He was brought to the operating room for repeat reduction pulmonary arterioplasty with a PTFE transannular patch. He has since been discharged home but continues to require ventilatory assistance at night.

\section{Reinterventions}

Patient 8 underwent initial repair with a reduction pulmonary arterioplasty and transannular patch with PTFE, from which he had an uneventful recovery. He was seen again 2 months later with a significant left branch PA stenosis and underwent balloon angioplasty at 3 months of age. He subsequently underwent stent placement of the left PA stenosis after a ventilation-perfusion scan demonstrated maldistribution of flow with $80 \%$ to the right lung; after the stent placement, he now demonstrates balanced pulmonary blood flow. Actuarial freedom from intervention (operation or $\mathrm{CBI}$ ) is represented in Figure 1.

\section{Functional Recovery and Airway Management}

Preoperative airway assessment with bronchoscopy was reserved for selected patients with significant airway

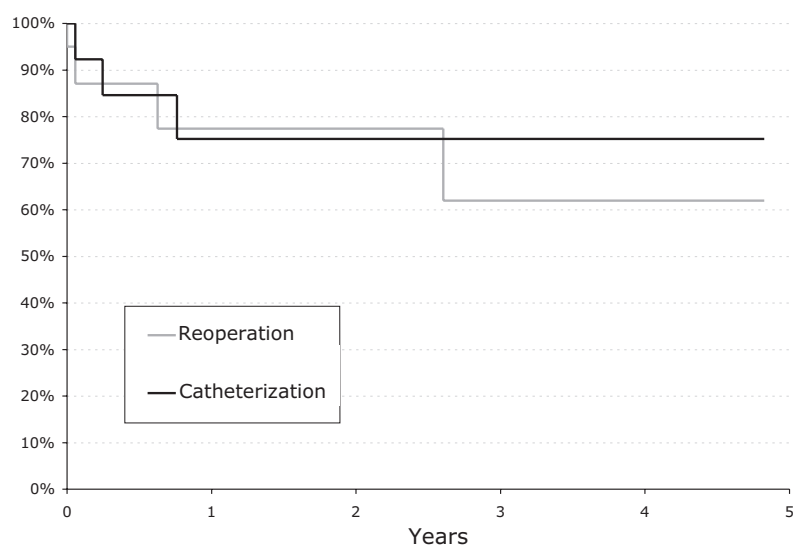

Figure 1. Actuarial freedom from intervention (reoperation or $\mathrm{CBI}$ ). 
obstruction requiring intubation. Three of the 5 patients who were intubated preoperatively had pneumothoraces develop, probably from high peak ventilatory pressures. One patient underwent preoperative MRI, and 1 patient underwent preoperative computed tomographic scan analysis; however, it is not our policy to pursue additional imaging in those patients for whom transthoracic echocardiography is definitive.

Of the entire cohort, 11 patients were discharged from the hospital with no respiratory symptoms. Only 1 patient (patient 20) required a tracheostomy (which he underwent before his arrival at MS-CHONY), and he remains ventilator dependent at night. One patient (patient 12) with severe bronchomalacia died of an apparent respiratory arrest (he had required home CPAP). Two patients (patients 10 and 13) were discharged home with bronchomalacia, as diagnosed by fiberoptic bronchoscopy, but now demonstrate no functional limitations. One patient (patient 14) was seen postoperatively with 2 years of obstructive airway symptoms (as manifested by inability to keep up with her peers in exercise) and subsequently underwent reoperation and revision of her reduction arterioplasty. Three patients were unavailable for follow-up. No patient has had formal exercise testing.

\section{Discussion}

APV syndrome is an uncommon variant, affecting only $3 \%$ to $6 \%$ of patients with TOF. In addition to the stigmata of TOF, those with APV characteristically demonstrate massively dilated PAs, thought to contribute substantially to tracheomalacia and bronchomalacia and thus to respiratory compromise in early life. Those with TOF-APV have traditionally been subdivided into two groups: those who have respiratory distress in the neonatal period and those who do not. This categorization in previous studies has also been thought to predict postoperative outcome, with those who have preoperative respiratory compromise having worse postoperative outcomes.

Substantial controversy persists in the literature regarding the management of the neonate with symptoms, with technical concerns regarding arterioplasty of the branch PAs and the establishment of the RV-PA connection. Most have advocated early intervention, although reported mortality for operation in the neonatal period has been considerable. We undertook this study to review our experience with primary repair of TOF-APV during a 15-year period. Our results are notable for four salient findings.

First, we continue to follow a strategy for early operative intervention for TOF-APV, even for patients without symptoms. If patients can be stabilized with CPAP, this procedure can be performed electively; those who require mechanical ventilation may also demand earlier operation, as air trapping, focal emphysema, and pneumothorax can result in those in whom emergency repair is accelerated by respiratory compromise.

Second, at the time of operation, we have found several technical points worthy of mention. First, we fully mobilize the branch PAs from hilum to hilum; it is also essential to excise all ductal tissue when present, because such tissue can result in residual branch pulmonary stenosis. In addition, at the time of reduction arterioplasty, it is important not to excise excessive amounts of tissue at the angle of the main pulmonary and right PA, because this can result in a too-acute angle of origin of the right PA, presaging the development of stenosis at this point. Similarly, for those who require unifocalization at the time of repair, particular attention must be paid to the angle of origin of the reimplanted PA to reduce the possibility of kinking and subsequent stenosis.

Third, we have not found it necessary to maintain a valved connection between the RV and the PA (and have had no experience with a PTFE monocusp valve in this setting), although others have suggested its necessity in the newborn period, when the likelihood of pulmonary hypertension is greatest. In addition, use of the direct connection technique brings the back wall of the main PA more anterior than in reconstruction with a homograft, and in this way may in fact by design bring the PAs more anterior (and off the bronchus) than other repair techniques. As with our experience in repair of truncus arteriosus, it would appear that patients treated with direct connection type techniques have not required reoperation such as would be obligatory with the use of a homograft connection in the neonatal period. $^{7}$

Fourth, the exercise tolerance of these children has been excellent. Even mild symptoms of exercise intolerance however, may reflect significant RV dilatation or hypertension. Close follow-up evaluation of these children by echocardiography and MRI is thus mandatory to evaluate longitudinally potential PA stenosis and RV dimensions and function. Many of the distal pulmonary stenoses can be managed percutaneously, but for patients who demonstrate significant perfusion mismatch (greater than 70\%/30\% discrepancy), a repeat pulmonary arterioplasty is often indicated.

In sum, we report excellent outcomes with early repair of TOF-APV, including for patients with severe tracheomalacia. Despite the relief of anterior compression of the tracheobronchial tree, however, bronchomalacia may persist, and thus such patients require assiduous follow-up. We have found ventilation-perfusion scans to be a simple, inexpensive means of assessing pulmonary flow distribution; however, MRI not only affords this assessment but further allows evaluation of PA anatomy, RV function, and regur- 
gitant fractions. It is hoped that future studies with longterm follow-up evaluation will help to delineate those patients who may require intervention to establish pulmonary valve competency.

\section{References}

1. McDonnell BE, Raff GW, Gaynor JW, Rychik J, Godinez RI, DeCampli WM, et al. Outcome after repair of tetralogy of Fallot with absent pulmonary valve. Ann Thorac Surg. 1999;67:1391-6.

2. Kreutzer C, Schlichter A, Kreutzer G. Tetralogy of Fallot with absent pulmonary valve: a surgical technique for complete repair. $J$ Thorac Cardiovasc Surg. 1999;117:192-4.
3. Kirshbom PM, Jaggers JJ, Ungerleider RM. Tetralogy of Fallot with absent pulmonary valve: simplified technique for homograft repair. J Thorac Cardiovasc Surg. 1999;118:1125-7.

4. Hew CC, Daebritz SH, Zurakowski D, del Nido PI, Mayer JE, Jonas RA. Valved homograft replacement of aneurysmal pulmonary arteries for severely symptomatic absent pulmonary valve syndrome. Ann Thorac Surg. 2002;73:1778-85.

5. Kirshbom PM, Kogon BE. Tetralogy of Fallot with absent pulmonary valve syndrome. Semin Thorac Cardiovasc Surg Pediatr Card Surg Аппи. 2004;7:65-71.

6. Hraska V. A new approach to correction of tetralogy of Fallot with absent pulmonary valve. Ann Thorac Surg. 2000;69:1601-3.

7. Chen JM, Glickstein JS, Davies RR, Mercando ML, Hellenbrand WE, Mosca RS, et al. The effect of repair technique on postoperative right-sided obstruction in patients with truncus arteriosus. $J$ Thorac Cardiovasc Surg. 2005;129:559-68.

Access to The Journal of Thoracic and Cardiovascular Surgery Online is reserved for print subscribers!

Full-text access to The Journal of Thoracic and Cardiovascular Surgery Online is available for all print subscribers. To activate your individual online subscription, please visit The Journal of Thoracic and Cardiovascular Surgery Online, point your browser to http://www.mosby.com/jtcvs, follow the prompts to activate your online access, and follow the instructions. To activate your account, you will need your subscriber account number, which you can find on your mailing label (note: the number of digits in your subscriber account number varies from 6 to 10). See the example below in which the subscriber account number has been circled:

Sample mailing label

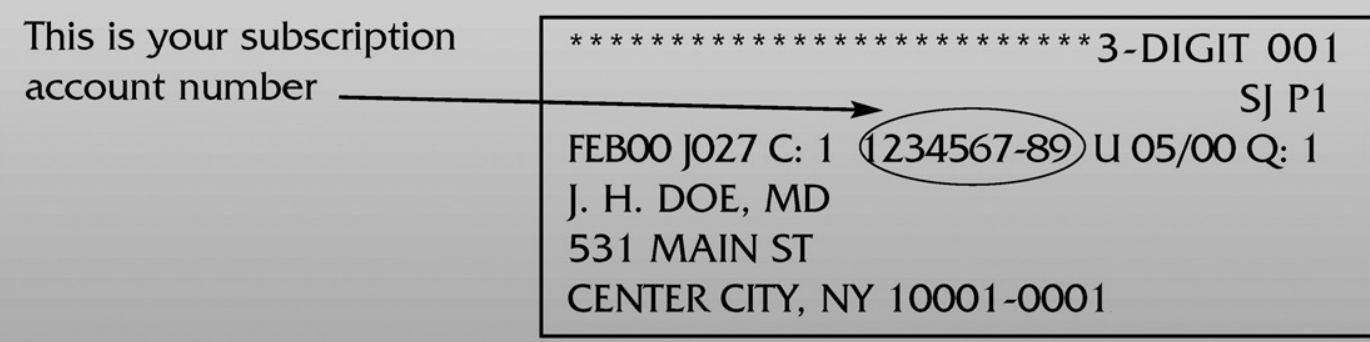

Personal subscriptions to The Journal of Thoracic and Cardiovascular Surgery Online are for individual use only and may not be transferred. Use of The Journal of Thoracic and Cardiovascular Surgery Online is subject to agreement to the terms and conditions as indicated online. 